\title{
The association between sleep duration, bedtimes, and early pubertal timing among Chinese adolescents: a cross-sectional study
}

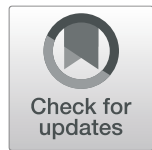

Hua Diao, Hong Wang ${ }^{*}$ (D), Lianjian Yang and Ting Li

\begin{abstract}
Background and objective: Early pubertal timing is associated with sleep among Western adolescents, but little is known about this association in Chinese adolescents, especially with regard to the association between bedtimes and early pubertal timing. This paper aimed to identify the association between sleep duration, bedtimes, and early pubertal timing in Chinese adolescents.
\end{abstract}

Methods: An anonymous cross-sectional survey was conducted among primary and junior middle students (grades 3 to 9) from QiJiang District, ChongQing, China. Participants were recruited by applying stratified cluster sampling. Pubertal timing, sleep duration, and bedtimes were assessed using the Pubertal Development Scale and a selfdesigned sleep questionnaire. We utilized multivariable logistic linear regression (MLLR) to test the association between sleep duration, bedtimes, and pubertal timing.

Results: A total of 5461 adolescents were evaluated, with mean age and BMI values of $11.41 \pm 2.05$ and $18.03 \pm$ 3.03, respectively, of whom 1257 (23.02\%) were in early pubertal timing. In MLLR controlling for age, BMI, family economic status, and other covariates, sufficient sleep $(b=-0.214, P=0.032, \mathrm{OR}=0.808,95 \% \mathrm{Cl} 0.664-0.982)$ was negatively related to early pubertal timing, and later bedtime $(b=0.195, P<0.001, \mathrm{OR}=1.215,95 \% \mathrm{Cl} 1.104-1.338)$ was positively associated with early pubertal timing.

Conclusion: Students with early pubertal timing had less sleep duration and later bedtimes, which may be the result of increased stress caused by physical and psychological changes. Therefore, more attention should be paid to pubertal health education for adolescents during puberty. Further longitudinal studies are needed to confirm the causality between sleep and early pubertal timing in Chinese adolescents.

Keywords: Early pubertal timing, Sleep duration, Bedtimes, Adolescents

\footnotetext{
* Correspondence: wangh111111@aliyun.com

School of Public Health and Management, Research Center for Medicine and

Social Development, Collaborative Innovation Center of Social Risks

Governance in Health, Chongqing Medical University, Chongqing 400016,

China
}

(c) The Author(s). 2020 Open Access This article is licensed under a Creative Commons Attribution 4.0 International License, which permits use, sharing, adaptation, distribution and reproduction in any medium or format, as long as you give appropriate credit to the original author(s) and the source, provide a link to the Creative Commons licence, and indicate if changes were made. The images or other third party material in this article are included in the article's Creative Commons licence, unless indicated otherwise in a credit line to the material. If material is not included in the article's Creative Commons licence and your intended use is not permitted by statutory regulation or exceeds the permitted use, you will need to obtain permission directly from the copyright holder. To view a copy of this licence, visit http://creativecommons.org/licenses/by/4.0/ The Creative Commons Public Domain Dedication waiver (http://creativecommons.org/publicdomain/zero/1.0/) applies to the data made available in this article, unless otherwise stated in a credit line to the data. 


\section{Background}

Adolescents are in a critical transition from childhood to adulthood that involves a sequence of physiological changes, such as growth spurts, the emergence of secondary sexual characteristics, and the development of gonads and genitals. The initial time of physiological changes is called pubertal timing [1,2]. Because of individual differences, pubertal timing can be divided into early, on time, and late compared with same-age and same-gender peers. Multiple studies have shown that the age at menarche and Tanner II breast development (B2) in developed countries is younger than that in the past [3-5]. Chinese children are also experiencing accelerated growth and advanced pubertal development, which has attracted the attention of Chinese experts [6-9]. In our previous studies, the average age at menarche in 2010 in urban areas of ChongQing was 0.26 years earlier than in 2005 [10]. The predominant determinant of early pubertal timing is genetic factors [11, 12], although the influence of environmental, social, and physical factors, such as gender, parental educational level, family structure, and body fat, are also indispensable [11, 13-17]. Early pubertal timing is not only associated with externalized behaviors such as aggression, smoking, drinking, and substance abuse but also closely related to internalized psychopathological symptoms such as anxiety, depression, and eating disorders [18, 19]. During adolescence, physiological and psychological upheavals are stressful events for children and adolescents [20], and early pubertal timing aggravates negative experiences such as conflicts between parents and children and conflicts among peers, resulting in difficulties in social adaptation and lower quality of life [21]. Therefore, early pubertal timing has attracted the attention of many researchers.

Sleep is crucial for adolescents' pubertal development [22-24], and there is a significant correlation between circadian sleep and early pubertal timing $[25,26]$. Hoyt et al. showed that the early development of breasts and pubic hair was related to sleep duration and bedtimes in black girls but not in Hispanic, white, and Asian girls [26]. Foley et al. indicated that the development of discrete aspects of secondary sex characteristics was uniquely associated with rhythm changes in sleep duration, eveningness preference, bedtimes, and wake times for girls but not for boys [25]. In China, some studies have found that sleep duration is relevant to the age and incidence of first spermatorrhea for boys and the incidence of menarche for girls [27-30], but few studies have explored the associations between bedtimes and early pubertal timing. Currently, there are few domestic or international studies on the relationship between sleep and youthfulness, and there are obvious individual and racial differences in both circadian sleep and pubertal timing. Therefore, the aims of this study are to identify the association between circadian sleep and early pubertal timing in Chinese adolescents. Our research presumes that insufficient sleep duration and later bedtimes increase the possibility of early pubertal timing in Chinese adolescents.

\section{Methods \\ Design and setting}

This research was a cross-sectional study. A multistage cluster sampling design was conducted to select 11 schools in Qijiang District, ChongQing. In stage 1, a better-cooperating district was selected in ChongQing. In stage 2, 6 primary schools and 5 junior middle schools were randomly chosen from this district. In stage 3, 6-8 classes were randomly selected from grades 3 to 6 in primary school and grades 7 to 9 in junior middle school. The selected 7446 students participated in our investigation, of whom 6991 (response rate 6991/7446 = 93.89\%) completed a 40-min questionnaire without obvious logical mistakes or missing items. The study was approved by the ethical committee of ChongQing Medical University, and written informed consent was obtained from students and their parents before the research was conducted. Data collection occurred during 1 week in December 2017.

\section{Measures}

1) Sociodemographic information Based on the influencing factors of pubertal timing in previous studies [11, 13-17], a self-designed questionnaire was applied to collect the following information: age, sex (male/female), whether there was only one child in the family (yes/no), parents' education level (low: junior middle school or lower; medium: senior middle school and technical secondary school; high: college or higher), family economic status (poor, medium, good), parents' relationship (poor, neutral, harmonious), and family parenting style (democratic: respectful, understanding, and supportive; autocratic: strict, with excessive behavioral regulation; doting; disregardful). BMI was calculated based on the formula weight in kilograms divided by height in meters squared. Height was accurate to within $0.1 \mathrm{~cm}$, and weight was accurate to within $0.1 \mathrm{~kg}$. Height and weight data were obtained from Qijiang Primary and Secondary School Students Health Care Center in ChongQing.

2) Pubertal timing

Pubertal timing was assessed by the Pubertal Development Scale (PDS) from Petersen and Crockett [31] involving 5 items (common items in boys and girls: growth spurt, pubic hair growth, skin change-pimples; items in boys only: 
deepening voice change, facial hair; items in girls only: breast development, menarche). Every entry except the item menarche has four options: "not yet started ( 1 point)," "barely started ( 2 points)," "definitely started (3 points)," or "seems completed (4 points)." The remaining item, whether menarche occurred, involves two options: yes (4 points) or no (1 point). The average score of all items was used to assess pubertal timing (early, on time, late). In this study, children with a score of P75 or higher were defined as early pubertal timing, those with scores between P25 and P75 were defined as the control group (on time), and those with P25 or lower were defined as late pubertal timing [10,32].

3) Sleep timing

Sleep duration (SD) and bedtimes (BT) were obtained through the following questions: (Q1), what time do you go to sleep on weekdays and weekends (hour, minute, am/pm); (Q2), what time do you get up on weekdays and weekends (hour, minute, am/pm)? The intervals between Q1 and Q2 were defined as the sleep duration on weekdays (SD1) and weekends (SD2), respectively. Sleeping times were defined as bedtimes on weekdays (BT1) and weekends (BT2). Average sleep duration (ASD) and average bedtime $(\mathrm{ABT})$ were calculated based on the following formulas: $\mathrm{ASD}=(\mathrm{SD} 1 \times 5+\mathrm{SD} 2$ $\times 2) / 7 ; \mathrm{ABT}=(\mathrm{BT} 1 \times 5+\mathrm{BT} 2 \times 2) / 7$. According to the standards of sleep duration recommended by the American Academy of Sleep Medicine in 2016 [33], students aged 6 to 12 years who slept less than $9 \mathrm{~h}$ and students aged 13 to 18 years who slept less than $8 \mathrm{~h}$ were classified into the "insufficient sleep group," and students with sleep times longer than the above criteria were classified into the "sufficient sleep group."

\section{Statistical analyses}

Data collation and analysis were conducted using Epidata 3.0 and SPSS 21.0. First, according to the PDS scores, early $(\geq$ P75) and on-time (P25-P75) pubertal timing were determined. Then, average sleep duration was categorized into a ternary variable with two categories, insufficient and sufficient, and bedtime was divided into two groups, $\leq$ $10 \mathrm{pm}$ and $>10 \mathrm{pm}$. Chi-squared and $t$ tests were employed to examine the unadjusted associations among average sleep duration, bedtime, and pubertal timing. Further multivariate analyses were conducted to examine whether average sleep duration and bedtime were associated with pubertal timing through multivariable logistic linear regression (MLLR) while controlling for covariates involving sex, only child, parents' education level, economic status, parents' relationship, parenting style, age, and BMI. In the multivariate analyses, all variables affecting pubertal timing were included, and all missing observations on any variables were excluded from the analysis. Any result with a $P$ value less than 0.05 was considered statistically significant.

\section{Quality control}

We tried investigation tools to identify any problems that might occur during the test. With the cooperation of local primary and secondary school health centers and permission from the headmaster, the investigation was implemented, trained investigators administered the survey in each class, and the investigation questionnaire was completed by every subject independently. All questionnaires were given to the students for completion and were then reviewed by the investigators immediately after completion to ensure that the students had completed the forms correctly.

\section{Results}

\section{Subject characteristics}

Among the 6991 subjects, the mean age and BMI were $11.41 \pm 2.05$ and $18.08 \pm 3.30$, respectively, the number of students with normal pubertal timing was 4204 (male/female 2223/1981), and the number of students with early pubertal timing was 1257 (boy/girl 666/591) (Table 1). Because of the analysis of the relationship between early pubertal timing and sleep quality, we removed the sample with late pubertal timing (1530). Among the students with early and normal pubertal timing, 2889 (52.9\%) were male, 2572 $(47.1 \%)$ were female, 1019 (18.7\%) were the only child, 4442 (81.3\%) were not the only child, 2760 (50.5\%) lived in a family with medium economic status, $4575(83.8 \%)$ came from families with harmonious parent relationships, and $3609(66.1 \%)$ were raised in a democratic parenting style. With regard to the subjects' mothers and fathers, 3209 (58.8\%) and $3161(57.9 \%)$ had a junior middle school or lower education, respectively.

Chi-squared and $t$ tests revealed that insufficient sleep duration was more prevalent among students whose parents had less education $(P<0.001)$, students with poor economic status $(P<0.001)$ and parents' relationship $(P$ $=0.033)$, and students with older age $(P<0.001)$ or higher BMI $(P<0.001)$. The results of later bedtime were similar: the bedtimes of females $(P<0.001)$ and only children $(P=0.044)$ were later; students who were the only child $(P=0.004)$ and students with higher BMI $(P<0.001)$ were more likely to undergo early pubertal timing; and parenting style significantly affected sleep duration $(P=0.046)$, bedtime $(P=0.014)$, and pubertal timing $(P=0.031)$. All results are shown in Table 2 . 
Table 1 The scores of important puberty timing events in adolescents aged 8-15 in QiJiang District, Chongqing

\begin{tabular}{|c|c|c|c|c|c|c|c|c|c|c|}
\hline \multirow[t]{2}{*}{ Age } & \multicolumn{2}{|c|}{ Male } & \multicolumn{3}{|c|}{ Pubertal timing, $N$} & \multicolumn{2}{|c|}{ Female } & \multicolumn{3}{|c|}{ Pubertal timing, $N$} \\
\hline & P25 & P75 & On time & Early & Late & P25 & P75 & On time & Early & Late \\
\hline 8 & 1.00 & 2.00 & 160 & 43 & 20 & 1.00 & 1.60 & 157 & 38 & 25 \\
\hline 9 & 1.20 & 1.80 & 278 & 97 & 158 & 1.00 & 1.60 & 378 & 83 & 46 \\
\hline 10 & 1.00 & 1.60 & 378 & 101 & 63 & 1.00 & 1.80 & 251 & 72 & 141 \\
\hline 11 & 1.00 & 1.60 & 351 & 110 & 46 & 1.40 & 2.20 & 241 & 97 & 131 \\
\hline 12 & 1.20 & 2.00 & 331 & 100 & 151 & 1.60 & 2.60 & 236 & 87 & 128 \\
\hline 13 & 1.60 & 2.40 & 290 & 89 & 148 & 2.20 & 2.80 & 297 & 92 & 119 \\
\hline 14 & 1.80 & 2.60 & 282 & 97 & 119 & 2.40 & 3.00 & 319 & 79 & 127 \\
\hline 15 & 2.00 & 2.80 & 153 & 29 & 49 & 2.45 & 3.00 & 102 & 43 & 59 \\
\hline Total & -- & -- & 2223 & 666 & 754 & -- & -- & 1981 & 591 & 776 \\
\hline
\end{tabular}

Table 2 Characteristics of adolescents with regard to sleep duration, bedtime, and pubertal timing

\begin{tabular}{|c|c|c|c|c|c|c|c|c|c|}
\hline \multirow[t]{2}{*}{ Characteristics, N (\%) } & \multicolumn{2}{|c|}{ Sleep duration X (SD)/N (\%) } & \multirow[t]{2}{*}{$P$} & \multicolumn{2}{|c|}{ Bedtime $X(\mathrm{SD}) / \mathrm{N}(\%)$} & \multirow[t]{2}{*}{$P$} & \multicolumn{2}{|c|}{ Pubertal timing $X(\mathrm{SD}) / \mathrm{N}(\%)$} & \multirow[t]{2}{*}{$P$} \\
\hline & Insufficient & Sufficient & & $\leq 10 \mathrm{pm}$ & $>10 \mathrm{pm}$ & & On time & Early & \\
\hline \multicolumn{10}{|l|}{ Sex } \\
\hline Male, 2889 (52.9) & $438(15.2)$ & $2451(84.8)$ & 0.840 & $2253(78.0)$ & $636(22.0)$ & $<0.001$ & $2223(76.9)$ & $666(23.1)$ & 0.948 \\
\hline Female, 2572 (47.1) & $395(15.4)$ & 2177 (84.6) & & $1894(73.6)$ & $678(26.4)$ & & $1981(77.0)$ & $591(23.0)$ & \\
\hline \multicolumn{10}{|l|}{ Only child } \\
\hline Yes, 1019 (18.7) & $163(16.0)$ & $856(84.0)$ & 0.465 & $749(73.5)$ & $270(26.5)$ & 0.044 & $750(73.6)$ & $269(26.4)$ & 0.004 \\
\hline No, $4442(81.3)$ & $670(15.1)$ & $3772(84.9)$ & & $3398(76.5)$ & $1044(23.5)$ & & $3454(77.8)$ & $988(22.2)$ & \\
\hline \multicolumn{10}{|l|}{ Father's education level } \\
\hline Low, 3161 (57.9) & $545(17.2)$ & $2616(82.8)$ & $<0.001$ & $2238(70.8)$ & $923(29.2)$ & $<0.001$ & $2408(76.2)$ & $753(23.8)$ & 0.118 \\
\hline Medium, 2108 (28.6) & $262(12.4)$ & $1846(87.6)$ & & $1741(82.6)$ & $367(17.4)$ & & $1653(78.4)$ & $455(21.6)$ & \\
\hline High, 192 (3.5) & $26(13.5)$ & $166(86.5)$ & & $168(87.5)$ & $24(12.5)$ & & $143(74.5)$ & $49(25.5)$ & \\
\hline \multicolumn{10}{|l|}{ Mother's education level } \\
\hline Low, 3209 (58.8) & $558(17.4)$ & 2651 (82.6) & $<0.001$ & $2249(70.1)$ & $960(29.9)$ & $<0.001$ & $2451(76.4)$ & $758(23.6)$ & 0.297 \\
\hline Medium, 2084 (38.2) & $244(11.7)$ & $1840(88.3)$ & & $1748(83.9)$ & $336(16.1)$ & & $1627(78.1)$ & $457(21.9)$ & \\
\hline High, 168 (3.0) & $31(18.5)$ & $137(81.5)$ & & $150(89.3)$ & $18(10.7)$ & & $126(75.0)$ & $42(25.0)$ & \\
\hline \multicolumn{10}{|l|}{ Economic status } \\
\hline Poor, 719 (13.2) & $120(16.7)$ & $599(83.3)$ & $<0.001$ & $525(73.0)$ & $194(27.0)$ & $<0.001$ & $547(76.1)$ & $172(23.9)$ & 0.168 \\
\hline Medium, 2760 (50.5) & $472(17.1)$ & $2288(82.9)$ & & $1915(69.4)$ & $845(30.6)$ & & $2103(76.2)$ & $657(23.8)$ & \\
\hline Good, 1982 (36.3) & $241(12.2)$ & $1741(87.8)$ & & $1707(86.1)$ & $275(13.9)$ & & $1554(78.4)$ & $428(21.6)$ & \\
\hline \multicolumn{10}{|l|}{ Parents' relationship } \\
\hline Poor, 177 (3.2) & $38(21.5)$ & $139(78.5)$ & 0.033 & $125(70.6)$ & $52(29.4)$ & 0.004 & $138(78.0)$ & $39(22.0)$ & 0.195 \\
\hline Neutral, 709 (13.0) & $117(16.5)$ & $592(83.5)$ & & $509(71.8)$ & $200(28.2)$ & & $527(74.3)$ & $182(25.7)$ & \\
\hline Harmonious, 4575 (83.8) & $678(14.8)$ & 3897 (85.2) & & $3513(76.8)$ & $1066(23.2)$ & & $1539(77.4)$ & $1036(22.6)$ & \\
\hline \multicolumn{10}{|l|}{ Parenting style } \\
\hline Democratic, 3609 (66.1) & $567(15.7)$ & $3042(84.3)$ & 0.046 & $2717(75.3)$ & $892(24.7)$ & 0.014 & $2794(77.4)$ & $815(22.6)$ & 0.031 \\
\hline Autocratic, 1012 (18.5) & $164(16.2)$ & $848(83.8)$ & & $756(74.7)$ & $256(25.3)$ & & $773(76.4)$ & $239(23.6)$ & \\
\hline Doting, 601 (11.0) & $70(11.6)$ & $531(88.4)$ & & $486(80.9)$ & $115(19.1)$ & & $471(78.4)$ & $130(21.6)$ & \\
\hline Disregardful, 239 (4.4) & $32(13.4)$ & 207 (86.6) & & $188(78.7)$ & $51(21.3)$ & & $166(69.5)$ & $73(30.5)$ & \\
\hline Age & $12.07(1.74)$ & $11.30(2.07)$ & $<0.001$ & $10.83(1.88)$ & $13.26(1.33)$ & $<0.001$ & $11.40(2.06)$ & $11.47(1.99)$ & 0.281 \\
\hline BMI & $18.90(3.36)$ & $17.94(3.27)$ & $<0.001$ & $17.66(3.30)$ & $19.43(2.92)$ & $<0.001$ & $17.94(3.26)$ & 18.57 (3.39) & $<0.001$ \\
\hline
\end{tabular}




\section{Association between sleep and pubertal timing}

Chi-squared tests showed that students with early pubertal timing were more susceptible to insufficient sleep duration $(P<0.001)$ and later bedtimes $(P<0.001)$ (Table 3).

MLLR was conducted to further explore the association controlling for covariates involving sex, only child, parents' education level, economic status, parents' relationship, parenting style, age, and BMI. MLLR (Table 4) revealed that sufficient sleep duration $(b=-0.214, P=$ 0.032 , OR $=0.808,95 \%$ CI $0.664-0.982$ ) was negatively related to early pubertal timing, and later bedtime $(b=$ $0.195, P<0.001$, OR $=1.215,95 \%$ CI $1.104-1.338)$ was positively associated with early pubertal timing.

Regarding the students' characteristics, early pubertal timing was more prevalent in students with higher BMI $(b=0.056, P<0.001, \mathrm{OR}=1.057,95 \%$ CI $1.037-1.078)$ and those with a disregardful parenting style $(b=0.143$, $P=0.007, \mathrm{OR}=1.512,95 \%$ CI $1.122-2.036)$. However, children with biological brothers or sisters $(b=-0.224$, $P<0.001$, OR $=0.800,95 \%$ CI $0.682-0.937)$ and older students $(\mathrm{b}=-0.096, P<0.001, \mathrm{OR}=0.90995 \% \mathrm{CI}$ 0.869-0.951) had less risk of early pubertal timing according to the MLLR (Table 4).

\section{Discussion}

Sufficient sleep is essential for adolescents' physical and mental well-being during adolescence. However, 66-92\% of adolescents do not get the recommended $8-10 \mathrm{~h}$ of sleep in the evening $[34,35]$. Insufficient sleep can have a huge negative impact on numerous adverse academic, safety, mental health, and physical health outcomes [3638]. Our results indicated that insufficient sleep and later bedtime were more prevalent among students whose parents had less education. Parents with a high degree of education are more likely to obtain sleep-related health knowledge through books, newspapers, and the Internet to help adolescents have healthy sleep [39]. The findings also showed that students with poor economic status and poor parent relationships were more susceptible to insufficient sleep duration and later bedtimes. The

Table 3 Unadjusted analyses between sleep duration, bedtime, and pubertal timing

\begin{tabular}{llllll}
\hline Sleep, N (\%) & \multicolumn{2}{l}{ Pubertal timing N (\%) } & $X^{2}$ & $P$ \\
\cline { 2 - 3 } & On time & Early & & \\
\hline Sleep duration & & & & \\
$\quad$ Insufficient, 833(15.3) & $580(69.6)$ & $253(30.4)$ & 30.003 & $<0.001$ \\
$\quad$ Sufficient, 4628(84.7) & $3624(78.3)$ & $1004(21.7)$ & & \\
Bedtime groups & & & & \\
$\leq 10$ pm, 4147(75.9) & $3246(78.3)$ & $901(21.7)$ & 16.216 & $<0.001$ \\
$>10$ pm, 1314(24.1) & $958(72.9)$ & $356(27.1)$ & & \\
\hline
\end{tabular}

Table 4 Standardized coefficients obtained from multiple logistic linear regression (MLLR)

\begin{tabular}{lllll}
\hline $\begin{array}{l}\text { Independent } \\
\text { variable(s) }\end{array}$ & \multicolumn{4}{l}{ MLLR $(\mathrm{N}=5461)$} \\
\cline { 2 - 5 } $\begin{array}{c}\text { Sleep duration } \\
\text { Insufficient }\end{array}$ & Ref & & & \\
Sufficient & -0.214 & 0.100 & 0.032 & $0.808(0.664-0.982)$ \\
Bedtimes (pm) $)^{\text {a }}$ & 0.195 & 0.049 & $<0.001$ & $1.215(1.104-1.338)$ \\
Sex & & & & \\
Male & Ref & & & \\
Female & -0.014 & 0.066 & 0.828 & $0.986(0.867-1.121)$ \\
Only child & & & & \\
Yes & Ref & & & \\
No & -0.224 & 0.081 & $<0.001$ & $0.800(0.682-0.937)$
\end{tabular}

Father's education level

$\begin{array}{lllll}\text { Low } & \text { Ref } & & & \\ \text { Medium } & -0.092 & 0.083 & 0.267 & 0.912(0.775-1.073) \\ \text { High } & 0.145 & 0.194 & 0.452 & 1.157(0.791-1.690)\end{array}$

Mother's education level

$\begin{array}{lllll}\text { Low } & \text { Ref } & & & \\ \text { Medium } & -0.028 & 0.083 & 0.735 & 0.972(0.826-1.144) \\ \text { High } & -0.009 & 0.209 & 0.996 & 0.991(0.658-1.492) \\ \text { Economic status } & & & & \\ \text { Poor } & \text { Ref } & & & \\ \text { Medium } & 0.005 & 0.100 & 0.958 & 1.005(0.826-1.224) \\ \text { Good } & -0.080 & 0.109 & 0.462 & 0.923(0.745-1.143)\end{array}$

Parents' relationship

Poor Ref

Neutral $\quad 0.273$

$\begin{array}{lllll}\text { Harmonious } & 0.185 & 0.190 & 0.332 & 1.203(0.828-1.747)\end{array}$

Parenting style

$\begin{array}{lllll}\text { Democratic } & \text { Ref } & & & \\ \text { Autocratic } & 0.035 & 0.087 & 0.689 & 1.035(0.873-1.228) \\ \text { Doting } & -0.052 & 0.110 & 0.636 & 0.949(0.765-1.178) \\ \text { Disregardful } & 0.143 & 0.152 & 0.007 & 1.512(1.122-2.036) \\ \text { Age } & -0.096 & 0.023 & <0.001 & 0.909(0.869-0.951) \\ \text { BMl } & 0.056 & 0.010 & <0.001 & 1.057(1.037-1.078)\end{array}$

The dependent variable was pubertal timing: on-time $=0$; early pubertal timing $=1$

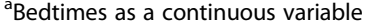

reason may be that a good family economy and harmonious parental relationship may create a good living environment for adolescents, thus reducing the incidence of negative life events and improving sleep quality. Additionally, the study found that individuals with older age or higher BMI had more insufficient sleep duration and later bedtimes. As adolescents become older, academic pressures increase, leading to sleep loss and later 
bedtime. Furthermore, overweight or obesity is a risk factor for many sleep breathing diseases [40, 41], which is consistent with our findings. The research also suggested that later bedtimes were predominant in only children. A previous study found that because the family is the initial living environment, parents have a profound role in children's sleep habits. Parents of only children, compared with those with multiple children, pay excessive attention to their child's sleep habits, leading to a greater susceptibility to the personality traits of cowardice and diffidence; these negative moods may result in poor sleep habits and sleep disorders [42].

Moreover, we found that students with early pubertal timing had less sleep duration and later bedtimes compared to their counterparts with on time puberty in the MLLR analysis, which is in accordance with reported findings in previous studies [25-28]. For instance, a study conducted by Foley et al. showed that girls with late bedtimes on weekdays had earlier pubic hair development and faster breast development during puberty [25]. In another study, Hoyt et al. found that early pubertal timing in girls was related to shorter sleep duration, but there was no association with pubertal rate [26]. In China, Wen et al. found that insufficient sleep for boys increased the probability of first spermatorrhea [27]. The reasons for shorter sleep duration and later bedtimes among students with early pubertal timing involve two aspects: sociopsychological factors and hormone secretion. First, the onset of puberty, which involves a sequence of physical and psychological upheavals, is a stressful event [20] that may lead to parental conflicts and peer conflicts. Earlier pubertal timing exacerbates these stresses [43, 44], giving rise to internalizing problems such as depression and anxiety [18, 19]. Furthermore, sleep duration and betimes may be influenced negatively. Second, increases in estrogen and insulingrowth factor 1 (IGF1) can promote the development of the breast and pubic hair, and adrenal androgens can stimulate the growth of pubic hair. This information indicates that maturation of the adrenal glands may negatively impact sleep duration and bedtime [25, 45]. Similarly, after adolescents enter puberty, their melatonin secretion time changes, leading to delays in sleep time and wakefulness [27]. A study conducted by Zwart et al. [46] showed that long-term melatonin treatment in adolescents with chronic sleep disorders can improve sleep quality and delay puberty initiation.

The association between less sleep duration, later bedtimes, and early pubertal timing can be recognized in the wider context of the influencing factors of pubertal timing. The data analysis indicated that the students with higher BMI have a higher risk of undergoing early pubertal timing, which is similar to previous studies [14, 15]. Insulin resistance in obese students decreases the level of sex hormone-binding protein in the liver, which increases estrogen levels and promotes pubertal development [15]. Earlier pubertal timing was prevalent among subjects with a disregardful parenting style, which is supported by Wang et al. [47]. This may be due to the lack of parental care, resulting in increased family pressure. Subjects with biological brothers or sisters were less sensitive to earlier pubertal timing. When these individuals face pubertal changes and stress during adolescence, they can communicate with their brothers or sisters to relieve stress. Younger students experienced earlier pubertal timing, which is inconsistent with the findings of Wen et al. [27]. The reasons for this divergence may be that they explored the association between the incidence of first spermatorrhea and age, and there was no clear definition of earlier first spermatorrhea.

\section{Limitation}

This research is a preliminary exploration of the association between sleep and early pubertal timing in Chinese adolescents, and as such, there are several limitations that should be considered in the interpretation of the results. First, the subjects in our study were from 11 selected schools in one district in Chongqing, which may not represent the whole population of adolescents. Furthermore, the study was a cross-sectional study, and we could not establish causality. Finally, sleep duration only involved sleep duration at night, which may have had an impact on the final results. Therefore, further studies are necessary to better detect the association between sleep and early pubertal timing.

\section{Conclusions and implications}

This study suggests that students with early pubertal timing have less sleep duration and later bedtimes. This may be the result of increased stress caused by physical and psychological changes. Therefore, more attention should be paid to pubertal health education for adolescents during puberty. Additionally, further longitudinal studies are needed to confirm the causality between sleep and early pubertal timing in Chinese adolescents.

\section{Supplementary information}

Supplementary information accompanies this paper at https://doi.org/10. 1186/s12199-020-00861-w.

Additional file 1. Approval notice of research paper.

Additional file 2. Analysis in both sexes (boys and girls).

Additional file 3. Relationship between parenting style and only child, sleep duration.

\section{Abbreviations}

SD: Sleep duration; BT: Bedtime; ASD: Average sleep duration; ABT: Average bedtime; MLLR: Multivariable logistic linear regression; GLLM: Generalized linear mixed model 


\section{Acknowledgments}

We would like to acknowledge the students who participated in the study and the teachers who helped to manage the students. We are very grateful to the primary and secondary school health care of Qijiang District in Chongqing. We are also grateful to the investigators who read and approved the manuscript.

\section{Authors' contributions}

$\mathrm{DH}$ was involved in the conception and design, literature search, data acquisition, data analysis, drafting of the initial manuscript, and critical revision for important intellectual content. WH, JF, and PY were involved in data acquisition, data analysis, and editing the manuscript. All authors read and approved the final manuscript.

\section{Funding}

This study was supported by the Social and Humanities Sciences Research Planning Fund Project from the Ministry of Education (17YJA840015). The funder had no role in the design, data collection, analysis, or interpretation of the data.

\section{Availability of data and materials}

All data generated or analyzed during this study are included in this published article and its supplementary documents.

\section{Ethics approval and consent to participate}

The study was approved by the Chongqing Medical University Committee. Written consent was obtained from every participant and the parents or guardians of minors involved in this study. The consent forms were approved by the Commission of Qijiang District.

\section{Consent for publication}

Not applicable.

\section{Competing interests}

The authors declare that they have no competing interests.

Received: 22 December 2019 Accepted: 12 June 2020 Published online: 19 June 2020

\section{References}

1. Wei C, Davis N, Honour J, Crowne E. The investigation of children and adolescents with abnormalities of pubertal timing. Ann Clin Biochem. 2017; 54(1):20-32. https://doi.org/10.1177/0004563216668378.

2. Sabageh $A O$, Sabageh D, Adeoye OA, Adeomi AA. Pubertal timing and demographic predictors of adolescents in Southwest Nigeria. J Clin Diagn Res. 2015;9(8):LC11-3. https://doi.org/10.7860/JCDR/2015/13582.6349.

3. Bravender T. Adolescents and the importance of parental supervision. Pediatrics. 2015;136(4):761-2. https://doi.org/10.1542/peds.2015-2658.

4. Herman-Giddens ME, Steffes J, Harris D, Slora E, Hussey M, Dowshen SA, et al. Secondary sexual characteristics in boys: data from the pediatric research in office settings network. Pediatrics. 2012;130(5):E1058-E68. https://doi.org/10.1542/peds.2011-3291.

5. Ibanez L, Ferrer A, Marcos MV, Hierro FR, de Zegher F. Early puberty: rapid progression and reduced final height in girls with low birth weight. Pediatrics. 2000;106(5):e72. https://doi.org/10.1542/peds.106.5.e72.

6. C-y J, Hu P-j, He Z-h. Secular growth trends in the Chinese urban youth and its implications on public health (in Chinese). J Peking Univ Health Sci. 2007; 39(2):126-31.

7. Sun Y, Tao F-B, Su P-Y, Mai J-C, Shi H-J, Han Y-T, et al. National estimates of the pubertal milestones among urban and rural Chinese girls. J Adolesc Health. 2012;51(3):279-84. https://doi.org/10.1016/j.jadohealth.2011.12.019.

8. Shi $\mathrm{H}$-J. A review of early pubertal timing and youth hygiene (2): adolescent health research should pay attention to pubertal timing (in Chinese). Chin J School Health. 2008;29(4):289-91.

9. Sun Y, Tao F, Su P-Y. National estimates of pubertal milestones among urban and rural Chinese boys. Ann Hum Biol. 2012;39(6):461-7. https://doi. org/10.3109/03014460.2012.712156

10. Fang $\mathrm{Q}$, Wang $\mathrm{H}, \mathrm{Cao} \mathrm{X}$, Chen $\mathrm{H}$. Puberty timing status and its correlation with childhood obesity in Chongqing city (in Chinese). J Hygiene Res. 2012; 41(4):562-5.
11. Greenspan LC, Lee MM. Endocrine disrupters and pubertal timing. Curr Opin Endocrinol Diabetes Obes. 2018;25(1):49-54. https://doi.org/10.1097/ MED.0000000000000377.

12. Wohlfahrt-Veje C, Mouritsen A, Hagen CP, Tinggaard J, Mieritz MG, Boas M, et al. Pubertal onset in boys and girls is influenced by pubertal timing of both parents. J Clin Endocrinol Metab. 2016;101(7):2667-74. https://doi.org/ 10.1210/jc.2016-1073.

13. Bourguignon J-P, Juul A, Franssen D, Fudvoye J, Pinson A, Parent A-S. Contribution of the endocrine perspective in the evaluation of endocrine disrupting chemical effects: the case study of pubertal timing. Hormone Res Paediatrics. 2016;86(4):221-32. https://doi.org/10.1159/000442748.

14. Bygdell M, Kindblom JM, Celind J, Nethander M, Ohlsson C. Childhood BMI is inversely associated with pubertal timing in normal-weight but not overweight boys. Am J Clin Nutr. 2018;108(6):1259-63. https://doi.org/10. 1093/ajcn/nqy201.

15. Li W, Liu Q, Deng X, Chen Y, Liu S, Story M. Association between obesity and puberty timing: a systematic review and meta-analysis. Int J Environ Res Public Health. 2017;14(10):1-13. https://doi.org/10.3390/ijerph14101266.

16. Luo Y. Association between unhealthy family structure with early puberty timing in children (in Chinese). Chonqing Medical University. 2016.

17. Tao F-B. A review of early pubertal timing and youth hygiene (5): psychosocial stress and early pubertal timing (in Chinese). Chin J School Health. 2008;29(7):577-80.

18. Pomerantz H, Parent J, Forehand R, Breslend NL, Winer JP. Pubertal timing and youth internalizing psychopathology: the role of relational aggression. J Child Fam Stud. 2017;26(2):416-23. https://doi.org/10.1007/s10826-016-0598-z.

19. Negriff S, Dorn LD, Pabst SR, Susman EJ. Morningness/eveningness, pubertal timing, and substance use in adolescent girls. Psychiatry Res. 2011;185(3): 408-13. https://doi.org/10.1016/j.psychres.2010.07.006.

20. Joinson C, Heron J, Lewis G, Croudace T, Araya R. Timing of menarche and depressive symptoms in adolescent girls from a UK cohort. Br J Psychiatry. 2011;198(1):17-23. https://doi.org/10.1192/bjp.bp.110.080861.

21. Carta MG, Preti A, Moro MF, Aguglia E, Balestrieri M, Caraci F, Dell'Osso L, Di Sciascio G, Drago F, Faravelli C, Hardoy MC, D'Aloja E, Cossu G, Calo S, Palumbo G, Bhugra D. Eating disorders as a public health issue: prevalence and attributable impairment of quality of life in an Italian community sample. Int Rev Psychiatr. 2014;26(4):486-92.

22. Sadeh A, Dahl RE, Shahar G, Rosenblat-Stein S. Sleep and the transition to adolescence: a longitudinal study. Sleep. 2009;32(12):1602-9.

23. Colrain IM, Baker FC. Changes in sleep as a function of adolescent development. Neuropsychol Rev. 2011;21(1):5-21. https://doi.org/10.1007/ s11065-010-9155-5.

24. Becker SP, Sidol CA, Van Dyk TR, Epstein JN, Beebe DW. Intraindividual variability of sleep/wake patterns in relation to child and adolescent functioning: a systematic review. Sleep Med Rev. 2017;34:94-121. https:// doi.org/10.1016/j.smrv.2016.07.004.

25. Foley JE, Ram N, Susman EJ, Weinraub M. Changes to sleep-wake behaviors are associated with trajectories of pubertal timing and tempo of secondary sex characteristics. J Adolesc. 2018;68:171-86 https://doi.org/10.1016/j. adolescence.2018.07.017.

26. Hoyt LT, Deardorff J, Marceau K, Laurent CA, Windham GC, Greenspan LC, et al. Girls' sleep trajectories across the pubertal transition: emerging racial/ ethnic differences. J Adolesc Health. 2018;62(4):496-503 https://doi.org/10. 1016/j.jadohealth.2017.10.014.

27. Wen B, Dong Y-H, Yang Z-G, Li Y-H, Dong B, Ma J. Association between sleeping time and age at spermarche among Chinese boys aged 11-18 year (in Chinese). Chin J School Health. 2018;39(8):1140-3.

28. Peng L-L, Wang H, He F, Cheng X-T, Wang L-Y, Jiang J-J. Association between age of first spermatorrhea and physical activity or sleeping time in boys (in Chinese). J Shanghai Jiao Tong Univ. 2017;37(3):394-7.

29. Wen B, Dong Y-H, Yang Z-G, Li Y-H, Dong B, Zhou Z-Y, et al. Association between sleeping time and onset of menarche among Chinese girls aged 9 to 14 years (in Chinese). Chin J Child Health Care. 2019;27(7):701-5. https:// doi.org/10.11852/zgetbjzz2018-0858 http://kns.cnki.net/kcms/detail/61.1346. R.20190227.1150.004.html.

30. Li KQ, Wang H, Guo J, Yuan BC, Guan PY. Associated factors related to first spermatorrhea and menarche among high and primary school students, in Chongqing (in Chinese). Chin J Epidemiol. 2016;37(2):169-73.

31. Petersen AC, Crockett L, Richards M, Boxer A. A self-report measure of pubertal status: reliability, validity, and initial norms. J Youth Adolesc. 1988; 17(2):117-33. 
32. Pantsiotou S, Papadimitriou A, Douros K, Priftis K, Nicolaidou P, Fretzayas A. Maturational tempo differences in relation to the timing of the onset of puberty in girls. Acta Paediatr. 2008;97(2):217-20. https://doi.org/10.1111/j. 1651-2227.2007.00598.x.

33. Paruthi S, Brooks L, D'Ambrosio C, Hall WA, Kotagal S, Lloyd RM, et al. Consensus statement of the American Academy of Sleep Medicine on the recommended amount of sleep for healthy children: methodology and discussion. J Clin Sleep Med. 2016;12(11):1549-61.

34. Ming X, Koransky R, Kang V, Buchman S, Sarris CE, Wagner GC. Sleep insufficiency, sleep health problems and performance in high school students. Clin Med Insights Circ Respir Pulm Med. 2011;5(10):71-9. https:// doi.org/10.4137/CCRPM.S7955.

35. Hirshkowitz M, Whiton K, Albert SM, Alessi C, Bruni O, DonCarlos L, et al. National Sleep Foundation's sleep time duration recommendations: methodology and results summary. Sleep Health. 2015;1 (1):40-3.

36. Thacher PV, Onyper SV. Longitudinal outcomes of start time delay on sleep, behavior, and achievement in high school. Sleep. 2016;39(2):271-81 https:// doi.org/10.5665/sleep.5426.

37. Shochat T, Cohen-Zion M, Tzischinsky O. Functional consequences of inadequate sleep in adolescents: a systematic review. Sleep Med Rev. 2014; 18(1):75-87. https://doi.org/10.1016/j.smrv.2013.03.005.

38. Vorona RD, Szklo-Coxe M, Lamichhane R, Ware JC, McNallen A, Leszczyszyn D. Adolescent crash rates and school start times in two central Virginia counties, 2009-2011: a follow-up study to a Southeastern Virginia study, 2007-2008. J Clin Sleep Med. 2014;10(11):1169-U18.

39. Wu W-W, Jiang $X-Y$, Zhang $X$, Zhu X-L. The status and influencing factors of sleep quality for institutional older people in Fuzhou (in Chinese). Chin $J$ Nurs. 2016;51(3):352-5.

40. Panagiotou M, Deboer T. Chronic high-caloric diet accentuates age-induced sleep alterations in mice. Behav Brain Res. 2019;362:131-9 https://doi.org/10 1016/j.bbr.2019.01.017.

41. Li W, Wu M, Yuan F, Zhang H. Sugary beverage consumption mediates the relationship between late chronotype, sleep duration, and weight increase among undergraduates: a cross-sectional study. Environ Health Prev Med. 2018;23(1):63.

42. Conley CS, Rudolph KD, Bryant FB. Explaining the longitudinal association between puberty and depression: sex differences in the mediating effects of peer stress. Dev Psychopathol. 2012;24(2):691-701. https://doi.org/10. 1017/S0954579412000259.

43. Hu L, He D, Jian $H$, et al. Analysis on the investigation results of the sleeping conditions of the pre-school only child (in Chinese). Matern Child Health Care China. 2006;21(02):264-6. https://doi.org/10.3969/j.issn.1001-4411.2006. 02.067 .

44. Sontag LM, Graber JA, Clemans KH. The role of peer stress and pubertal timing on symptoms of psychopathology during early adolescence. J Youth Adolesc. 2011;40(10):1371-82. https://doi.org/10.1007/s10964-010-9620-8.

45. Campbell IG, Grimm KJ, de Bie E, Feinberg I. Sex, puberty, and the timing of sleep EEG measured adolescent brain maturation. Proc Natl Acad Sci U S A. 2013;109(15):5740-3.

46. Zwart TC, Smits MG, Egberts TCG, Rademaker CMA, van Geijlswijk IM. Longterm melatonin therapy for adolescents and young adults with chronic sleep onset insomnia and late melatonin onset: evaluation of sleep quality, chronotype, and lifestyle factors compared to age-related randomly selected population cohorts. Healthcare. 2018;6(1):1-16. Doi:10.3390/ healthcare6010023.

47. Wang J, Liu A-S. The influence of absence of father on the pubertal timing (in Chinese). Chin J School Health. 2015;36(1):158-60.

\section{Publisher's Note}

Springer Nature remains neutral with regard to jurisdictional claims in published maps and institutional affiliations.

Ready to submit your research? Choose BMC and benefit from:

- fast, convenient online submission

- thorough peer review by experienced researchers in your field

- rapid publication on acceptance

- support for research data, including large and complex data types

- gold Open Access which fosters wider collaboration and increased citations

- maximum visibility for your research: over $100 \mathrm{M}$ website views per year

At BMC, research is always in progress.

Learn more biomedcentral.com/submissions 